\title{
Alpha-1 antitrypsin (AAT) and C-reactive protein (CRP) in interstitial lungs diseases.
}

\author{
Desh Deepak Singh* \\ Amity Institute of Biotechnology, Amity University Rajasthan, India
}

\begin{abstract}
Deficiency of Alpha-1 Antitrypsin deficiency (AAT) and higher CRP level are known biomarker for Lungs diseases. The purpose of this investigation was to estimate probable relations of AAT and CRP levels in the Lungs diseases. The sera of 27 patients of Emphysema, 20 patients with Chronic Obstructive Pulmonary Disease (COPD) and 17 patients of asthma along with 28 healthy volunteers were analysed. Age of patients and healthy volunteers was between 23 to 46 and male and female percentage was $71 \%$ and $29 \%$ respectively. Serum AAT in asthma $(0.401 \pm 0.340)$, COPD $(0.556 \pm$ $0.310)$ and of emphysema $(0.421 \pm 0.311)$ is significant $(P<0.001)$ lower than healthy control $(1.01 \pm 0.17)$. Serum CRP in asthma $(3.930 \pm 0.906)$, COPD $(3.830 \pm 0.666)$ and of emphysema $(3.996 \pm 1.049)$ is higher than healthy control $(1.01 \pm 0.17)$. Thus, serum AAT and CRP measurement can be helpful in predicting asthma control and treatment response.
\end{abstract}

Keywords: Emphysema, Alpha 1-antitrypsin, COPD, Asthma, CRP.

Accepted on February 14, 2018

\section{Introduction}

Lungs disease is a common and curable disease characterized by insistent airflow restriction that is regularly liberal and related with an enhanced chronic inflammatory response in the airways and the lungs to harmful particles or gases. Exacerbations and comorbidities pay to the overall severity in specific patients $[1,2]$. Lungs disease is presently the fourth leading cause of death and a substantial social burden throughout world, particularly in underdeveloped countries. AAT is reported to be associated with the rapidly progressive Lungs disease. The condition is characterized by predominantly lower zone emphysema, the presence of chronic bronchitis [1], and bronchiectasis [2]. The pathogenesis of these features is not conclusive but is thought to be a direct result of Lungs damage by neutrophil elastase and causes COPD and Lungs cancer [3]. The critically low level of AAT predicted to be present in the Lungs interstitial [4] and in the airway [5] greatly enhances the amount and area of activity of neutrophil elastase [6] and hence the degree of Lungs damage. The study undertaken here indicates that deficiency of alpha1antitrypsin is also a factor to pulmonary infections.

\section{Material and Methods}

The study population consisted of 64 patients and 28 healthy volunteers. All the patients sample were obtained from the different hospitals of central India. All the patients had airflow obstruction with an FEV $1<55 \%$ of predicted. Age group of patients was 23-46 y and male and female percentage was 71 and 29 respectively. After an appropriate physical examination like GOLD stage: I/II/IV, smokers, pulmonary symptoms, thorax High-Resolution Computed Tomography (HRCT) findings, any type of emphysema, FVC (Forced Vital Capacity), FEV1 (Forced Expiratory Volume in 1), \% predicted, FEV1/FVC, TLC (Total Lungs Capacity), RV (Residual Volume), data on the symptoms of the patient was collected.

Blood samples were taken in serum tubes, clotted at normal room temperature for 35-65 min and centrifuged for $15 \mathrm{~min}$ at $4,000 \mathrm{rpm}$. Then, the samples were frozen at $-70^{\circ} \mathrm{C}$ for further analysis. The serum levels of AAT were determined by nephelometry using commercial kits (Dade Behring Marburg $\mathrm{GmbH}$, Marburg, Germany) according to the manufacturer instructions. The analysis of C-reactive protein (CRP) was measured by chemiluminescent immunoassay. The levels of CRP were expressed in $\mathrm{mg} / \mathrm{L}$.

Quantitative variables were articulated as means with standard deviations. Variances of quantitative data were evaluated by the Kruskal-Wallis H-test. Associations between variables were determined by the Spearman correlation test. A p-value of less than 0.05 was measured statistically significant. Arithmetic examination was achieved using IBM SPSS Statistics for Windows, Version 20.0.

\section{Results}

Out of 64 patients, 27 were found to be positive for emphysema, 20 patients for COPD and 17 patients positive for asthma. Age of patients and control was 23 to 46 and male and female ratio was $71 \%$ and $29 \%$ respectively, GOLD stage of 
I/II/IV was observed 4/10/50 respectively in total patients. History of smoking was found in 35 patients; ex-smokers were 16 and never-smokers were 13 patients. Pulmonary symptoms of patients were also recorded as dyspnoea in 32 patients, cough in 25 patients and chest pain was observed in 6 patients. Thorax High-Resolution Computed Tomography (HRCT) findings was observed in Saber sheath trachea with tracheal index $<0.67$ in 10 cases, thoracic cage ratio $>0.75$ at carina in 9 cases, thoracic cage ratio $>0.75$ at $5 \mathrm{~cm}$ below carina in 8 cases, sterno-aortic distance $>4 \mathrm{~cm}$ in 7 cases, directly visible small airways in 8 cases, mosaic attenuation pattern in 5 cases, vascular distortion in 4 cases and thoracic cross-sectional area $/ \mathrm{ht}^{2}>\mathrm{cm}^{2} / \mathrm{m}^{2}$ was observed in 13. Different types of emphysema observed in 27 cases such as paraseptal in 9 cases, panacinar in 6 cases and centriacinar type of emphysema in 11 and directly visible small airways was observed in 2 cases; mean of FVC was $100 \pm 5$, and FEV was $130 \pm 5$ observed. Mean of the ratio of FEV1/FVC was investigated as $453 \pm 3$, mean of TLC was $700 \pm 5$ and at mean level of RV was found as $221 \pm 15$.

Serum AAT was observed in asthma $(0.401 \pm 0.340)$, COPD $(0.556 \pm 0.310)$ and of emphysema $(0.421 \pm 0.311)$ which was observed as significant $(\mathrm{P}<0.001)$ lower than healthy control $(1.01 \pm 0.17)$. Serum CRP level was investigated in asthma $(3.930 \pm 0.906)$, COPD $(3.830 \pm 0.666)$ and of emphysema $(3.996 \pm 1.049)$ which was found as significant $(\mathrm{P}<0.001)$ higher than healthy control $(1.01 \pm 0.17)$. Thus, serum AAT and CRP measurement can be helpful in predicting asthma control and treatment response.

\section{Discussion}

This study showed the AAT and CRP value to compare with the severity of the Lungs diseases and scientific performance. These consequences are in support of the established fact that emphysema, COPD and asthma is a systemic inflammatory disease which primarily affects the Lungs. Comparable results were obtained in the studies which suggest that the reduced Lungs function in COPD, Asthma, emphysema is associated with increased levels of systemic inflammatory markers [7-12]. Statistically substantial association was found between the level of CRP and AAT. This result could be of excessive useful because it strength recommend that CRP and AAT level dependent predictors of systemic inflammation. Inflammatory response at the Lungs level to harmful agents causes systemic inflammatory changes and causes substantial extrapulmonary belongings that contribute to the increase of CRP and reduced to AAT.

\section{Conclusion}

The CRP level and AAT in lungs diseases exacerbation could be clinical marker for early diagnosis and patient's treatment management.

\section{Acknowledgements}

Authors are highly gratefully to acknowledge Dr. Vinod Singh, Department of Microbiology, Barkatullah University, Bhopal-462026 and Cancer Hospital Gwalior, who has been planned and cooperated in sample collection and experimental work from central India, who has been died due to cancer on dated 26 September 2017. Authors also gratefully acknowledge to MLB Medical College Jhansi- India, Peoples Medical College Bhopal. Government Medical College Gwalior and Medical University, Lucknow, India, Medical College, Kanpur, India. Author tanksful to Prof. G. L. Sharma, Institute of Genomics and integrative Biology Mall Road Delhi University Campus-India and finally thankful to Institute of Biomedical Sciences Bundelkhand university Jhansi.

\section{References}

1. Mackay AJ, Donaldson GC, Patel AR, Jones PW, Hurst JR, Wedzicha JA. Usefulness of the chronic obstructive pulmonary disease assessment test to evaluate severity of COPD exacerbations. Am J Respir Crit Care Med 2012; 185: 1218-1224.

2. Global Initiative for Chronic Obstructive Lungs Disease. Global strategy for the diagnosis, management, and prevention of chronic obstructive pulmonary disease. 2013. Available from: http: //www.goldcopd.com. Accessed November20, 2013.

3. Murray CJL, Lopez AD. Alternative projections of mortality and disability by cause 1990-2020. Global burden of disease. Lancet 1997; 349: 1498-1504.

4. Eden E, Mitchell D, Mehlman B, Khouli H, Nejat M, Grieco MH. Atopy, asthma, and emphysema in patients with severe alpha-1-antitrypysin deficiency. Am J Respir Crit Care Med 1997; 156: 68-74.

5. Stoller JK, Snider GL, Brantly ML. American Thoracic Society/European Respiratory Society Statement: standards for the diagnosis and management of individuals with alpha-1 antitrypsin deficiency. Am J Respir Crit Care Med 2003; 168: 818-855.

6. Fun Z, Yang P. Neutrophil elastase and alpha-1 antitrypsin: the role of imbalance in cancer development and progression: a review. Lancet Oncol 2004; 5: 182-190.

7. Stockley RA, Turner AM. Alpha-1-Antitrypsin deficiency: clinical variability, assessment, and treatment. Trends Mol Med 2014; 20: 105-115.

8. Stockley RA, Edgar RG, Pillai A, Turner AM. Individualized Lungs function trends in alpha-1-antitrypsin deficiency: a need for patience in order to provide patient centered management? Int J Chron Obstruct Pulmon Dis 2016; 11: 1745 .

9. Green CE, Vayalapra S, Hampson JA, Mukherjee D, Stockley RA, Turner AM. PiSZ alpha-1 antitrypsin deficiency (AATD): pulmonary phenotype and prognosis relative to PiZZ AATD and PiMM COPD. Thorax 2015; 70: 939-945. 
10. Gøtzsche PC, Johansen HK. Intravenous alpha-1 antitrypsin augmentation therapy for treating patients with alpha-1 antitrypsin deficiency and Lungs disease. Cochrane Database Syst Rev 2016; 9: 007851.

11. Lee TM, Lin MS, Chang NC. Usefulnes of C-reactive protein and interleukin- 6 as predictors of outcomes in patients with chronic obstructive pulmonary disease receiving provastatin.Am J Cardiol 2008; 101: 530-535.

12. Karadag F, Kirdar S, Kurul AB, Ceylan E. The value of Creactive protein as a marker of systemic inflammation in stable chronic obstructive pulmonary disease. Eur J Internal Med 2008; 19: 104-108.

\section{*Correspondence to}

Desh Deepak Singh

Amity Institute of Biotechnology

Amity University

India 